\title{
Developing Communication Skills during Undergraduate Studies: a Personalized Approach
}

\author{
Sylvie Hertrich and Dominique Chassé \\ Pedagogical Support Office \\ Polytechnique Montréal \\ sylvie.hertrich@polymtl.ca
}

\begin{abstract}
It is no wonder that communication skills are among the twelve attributes required by the Canadian Engineering Accreditation Board, since engineers must possess strong oral and written communication skills. At Polytechnique Montréal, all undergraduate students have been required to take a mandatory credit for this specific "soft-skill" since 2006.

As an alternative to the classical one-term class, this three-year long innovative educational strategy is based on a personalized approach. The first year, after taking diagnostic tests in written and oral communication, students attend communication workshops. They then perform realistic communication tasks in engineeringrelated situations, both at school and during an internship. Each year, they complete an e-portfolio and reflect on the development of their communication skills.

This method demonstrates the academic and professional transversality of a program-based approach. It also allows for practical assessment of complex engineering concepts reflecting the underlying philosophy of the twelve attributes.
\end{abstract}

Keywords: oral and written communication, programbased approach, descriptive analytic grid, e-portfolio, communication workshops, transversal competences, innovation, twelve attributes, metacognition.

\section{INTRODUCTION}

Polytechnique Montréal is Québec's largest francophone engineering school with over 7000 students, approximately 5000 of whom are enrolled in an undergraduate program. The school is renowned for its wide range of engineering specialties. It is also known as a teaching and research leader.

While technical communication has been taught since 1984 at Polytechnique Montréal as part of a three-credit methodology class, the need for improved communication skills became more acute following concerns expressed by the school's professional and industrial partners. The Canadian Engineering Accreditation Board also underscored the importance of achieving a better balance between non-technical skills, academic training and genuine industrial needs.

In 2004, a review of the undergraduate programs led to the addition of compulsory credits for the so-called "soft skills". Starting in 2006, each program included two new credits for interpersonal relations and teamwork skills and one new credit for oral and written communication.

In line with the program-based approach, oral and written communication was developed with an innovative pedagogical focus. This was done to promote a studentcentred practice and create strategic links between the academic and professional training. Almost a decade later, a large number of engineering students have benefited from this method and faculty is progressively becoming more involved.

\section{AN INNOVATIVE PEDAGOGICAL STRATEGY}

\subsection{Developing communication skills}

In the early 2000s, there was a wide consensus between Polytechnique's management, faculty, industrial partners and graduates for improved communication skills training and education. This was deemed essential to good engineering practice.

Apparently this was not an isolated situation. In the United States, many schools and universities recently added oral and written communication to their degree courses in order to meet expanding challenges [1]. The increasing responsibilities of our modern engineers and the part they play in multidisciplinary teams require a wide range of effective communication abilities.

In the past, dedicated courses were an obvious and often valued approach to improve students' communication skills. However a lack of learner interest and motivation, heavy course loads and a limited pedagogical timeframe at the beginning of undergraduate studies were detrimental to learning these soft skills. A robust pedagogical strategy was therefore put in place for the 1300 students entering Polytechnique each year. 


\subsection{A personalized approach}

Since very few students believe they need to improve their communication skills, some basic written and oral diagnostic testing is required from the time they enter the institution. Referring to a diagnostic is also consistent with the cognitive psychology tenet that learning builds on prior knowledge [2].

After being given a reference document that they read in advance, students are asked to write a short text of 450 words in response to simple instructions. These tests are presently conducted in computer laboratories and the results are directly transferred to the Moodle platform for assessment. Unlike handwritten tests, these essays are prepared using online tools such as a dictionary and the revision guide. In previous years, students had requested access to the usual language tools to write their test. The computerized version of the diagnostic written test reflects the effective use of French-language skills grammar, spelling, style -, and the related tools.

Students are then asked to prepare and give a short talk on a technical subject (8-10 minutes) using an appropriate visual aid (PowerPoint, Prezi).

Descriptive analytic rubrics are made available in advance and used by communication tutors to assess specific outcomes. Assessment codes and grids harmonize evaluation and students quickly become familiar with the terms and objectives. Personalized comments made by tutors accompany each assessment to provide constructive feedback and encourage student' progress. All results are entered into the "ÉvalCÉO" dynamic communication database.

Students who do not achieve the level of "good" are assigned to specific communication workshops. This approach responds to individual needs and promotes greater homogeneity in the classrooms. Appendix A presents the written and oral process outline.

The three-year process requires a coordination team for communication, workshops and e-portfolio support. Three part-time employees are supervised by a permanent professional and manage a team of approximately 15 communication tutors and workshop instructors. Costs are therefore slightly higher than for a single-term specialty course, but results show higher achievement and significant added value for the program-based approach.

\subsection{A progressive assessment sequence}

After students receive their diagnostic assessment in oral and written communication, they are asked to meet their workshop requirement by the end of the following term. A formative sequence immediately follows diagnostic evaluation and fosters prompt potential output in other course-related communication situations.
Workshops target declarative and procedural knowledge in a dynamic and interactive 90-minute classroom session. After each workshop, students are required to write an assignment that must be submitted via Moodle within 10 school days. The instructor then sends feedback to all participants and completes the evaluation process, before putting an answer key online.

Students register for the workshops online, via Moodle.

In the 2014 winter term, a total of 104 workshops were given on a variety of topics, in oral and written communication. Table 1 lists the workshops.

\begin{tabular}{|l||}
\hline Table 1: Communication workshops (winter 2014) \\
\begin{tabular}{|l|c|}
\hline Workshops (50 students/session) & Number \\
\hline Written communication & \\
\hline Text organization & 9 \\
\hline Grammar & 8 \\
\hline Quotations and references & 7 \\
\hline Tables and figures & 6 \\
\hline Vocabulary and style & 5 \\
\hline Résumé writing & 20 \\
\hline \hline CIV - Writing methods & 4 \\
\hline CIV - Structuring a report & 4 \\
\hline CIV - Tables, figures and graphs & 4 \\
\hline CIV - Writing aids & 4 \\
\hline \hline \multirow{2}{*}{ Oral communication } & \\
\hline Visual aids & 4 \\
\hline General communication skills & 4 \\
\hline Presentation preparation & 5 \\
\hline Job interview & 20 \\
\hline
\end{tabular}
\end{tabular}

Since 2013, four specific workshops are compulsory for all civil engineering students. They are led by specialty professors to meet that department's needs for better technical writing skills. It also demonstrates faculty's real interest for communication issues. This valuable professional assistance reinforces the need for effective communication in engineering programs, and more such opportunities would help spread disciplinespecific communication knowledge.

Once they have completed all of their communication workshops, students are ready to use their knowledge in new communication situations. Nevertheless, they are also asked to complete an annual e-portfolio that includes their communication productions and workshop 
assignments. As a collection of selected works [3], the eportfolio represents the students' communication skills achievements over time. The portfolio also contains an assessment completed once a year in which students reflect on their skills development. This reflective exercise helps consolidate new knowledge. It also draws on metacognition and regulation, which are directly linked to judgement and autonomy [4], two desired qualities for future engineers.

Final assessments are related to third-year projects and work placements in order to create connections between academic and professional knowledge. These learning situations are particularly relevant in terms of conditional knowledge. Communication tutors use the same descriptive analytic grids in order to determine progress and to assess if the competence has been reached.

This evaluation sequence (diagnostic, formative and summative) is an effective method to measure progress over time. Communication skills require authentic practice and feedback from engineering faculty and communication professionals.

\subsection{Better learning through an experiential approach}

The communication course is staggered over a threeyear period, because the types of skills it teaches need to be practiced at school and in a professional training context. What students learn in one class can be experienced or reproduced in another as well as in the workplace. Authentic tasks in discipline-related situations increase students' motivation by enhancing the perceived task value, its feasibility and the students' ownership on the task [5].

This long-term and somewhat constructivist approach focuses on revealing significant changes and outcomes with respect to learning and practice. It strengthens procedural knowledge and prepares students for more complex situations. As students become familiar with the communication culture of their discipline, they also engage in its maturing, becoming actively involved in their learning process.

It is therefore only natural that the final exams in oral and written communication are highly contextualized. They are related to third-year project courses and professional training, where higher taxonomic stages can be observed (Bloom's analysis, synthesis and evaluation). These authentic situations come under the basic comprehension of what a competence is: a complex "knowing-how-to-act" that draws on a combination of resources. Through progressive practice, this competence has a better chance of becoming permanent [2].

\subsection{A program-based approach and an interesting link with the twelve attributes}

The program-based approach is a teaching model that focuses on students' engagement and the instructors' global knowledge of the program components. As opposed to the single-class approach, the program-based approach is defined by a specific training project and the synergy aimed at achieving this goal by all leading participants [6]. Interestingly, the single-credit oral and written communication course incorporates the skill development concept, given that students are directly involved in the learning process for three years.

Furthermore, students get to practise their communication abilities in engineering-related situations at school and during their work placement. This longterm strategy enhances contextualized tasks. It is aligned with engineers' specific role in complex professional situations. It also promotes academic and professional transversality of the program-based approach. These naturally authentic situations foster "know-how" that activates different kinds of knowledge: theory, experiential, procedural, relational and cognitive skills. This knowledge determines the essence of a competence [7].

Matching oral and written communication with thirdyear projects and work training strengthens the connection with programs and placement services. This optimizes an educational project in which there is a clear idea of the value, attitudes and competences students need to develop. It also enhances the pedagogical measures used to achieve this aim [6]. Among the developed values, the communication course stimulates autonomy, responsibility and personal involvement in the learning process.

The program-based approach strives for continuous improvement as does the vision of the twelve attributes. Like ABET [8], both generate an exit profile and measure various knowledge elements. The oral and written communication instruction at Polytechnique Montréal is completely aligned with the seventh attribute (communication skills):

- Descriptive analytic rubrics focus on the appropriate demonstration of quality by measuring the degree of autonomy, work performed and complexity/infrequency of the situation;

- The progressive assessment sequence allows for structured and practical learning with constructive feedback in tandem with the programs' aims;

- Assessments allow for documented student outcomes and program improvement via the eportfolio; and,

- Continuity and connection with programs and services are enhanced. 
For optimal functioning of the communication course, a coordination team provides support and guidance for students and communication tutors.

\section{CONCLUSIONS}

At Polytechnique Montréal, the personalized and highly contextualized approach to oral and written communication prepares students for real-life complex engineering-related situations where they will be required to use coherent recipient-oriented communication strategies. The aim is to hone specific language use as well as information and technologies communication abilities.

This process also demonstrates obvious links with the twelve attributes, since outcomes can be compared at the beginning (diagnostic tests) and end (final exams) of the process. The progressive assessment sequence is useful for personal as well as program purposes. Transversality optimizes knowledge mobilization and ensures higher student learning outcomes due to realistic disciplinespecific tasks. These results are in line with the engineer's role on a professional multidisciplinary team often associated with contemporary participative management.

The personalized approach stimulates motivation and encourages autonomy since this three-year process is a clean break from the traditional one-term courses. Some students appreciate the fact that the diagnostic and communication situations enhance their abilities. Others find themselves challenged by some of the organization requirements (attending workshops, filling out an eportfolio) and by assessing their long-term improvement.

The course outline given in Appendix A shows that further improvement could be made to the formative sequence. One potential enhancement involves offering practical communication coaching in second-year project courses to support students and engineering faculty.

To reinforce and adjust to the vision of the twelve attributes, a new school portfolio similar to an e-portfolio is in the works (Polyfolio). The communication eportfolio will thus soon merge with the Polyfolio to simplify overall assessment and improvement.

The written and oral communication course clearly meets academic and professional expectations. The individualized and highly contextualized long-term approach associated with self-reflective practice yields higher learning achievement and may well drive the idea of continuing education that is so fundamental to engineers.
[2] Jacques Tardif, L'évaluation des compétences. Montréal : Chenelière éducation, 2006, pp. 14-51.

[3] Gérard Scallon, L'évaluation des apprentissages dans une approche par compétences. Saint-Laurent : ERPI, 2004, pp.285-314.

[4] Lise St-Pierre, "L’habileté d'autoévaluation : pourquoi et comment la développer ?", Pédagogie collégiale, vol. 18, no. 1 , p.33-38.

[5] Roland Louis, L'évaluation des apprentissages en classe. Laval : Beauchemin, 2004, pp.1-17.

[6] Richard Prégent, Huguette Bernard and Anastassis Kozanitis, Enseigner à l'université dans une approcheprogramme. Montréal : Presses internationales de Polytechnique, 2009, 330 pp. \{ISBN 978-2-553-01435-2\}

[7] Guy Le Boterf, De la compétence : essai sur un attracteur étrange. Paris : Éditions d'organisations, 1994, pp.165.

[8] ABET. Criteria for Accrediting Engineering Programs, 2014-2015. Available from http://www.abet.org/eac-criteria2014-2015/

APPENDIX A: Written and oral process outline

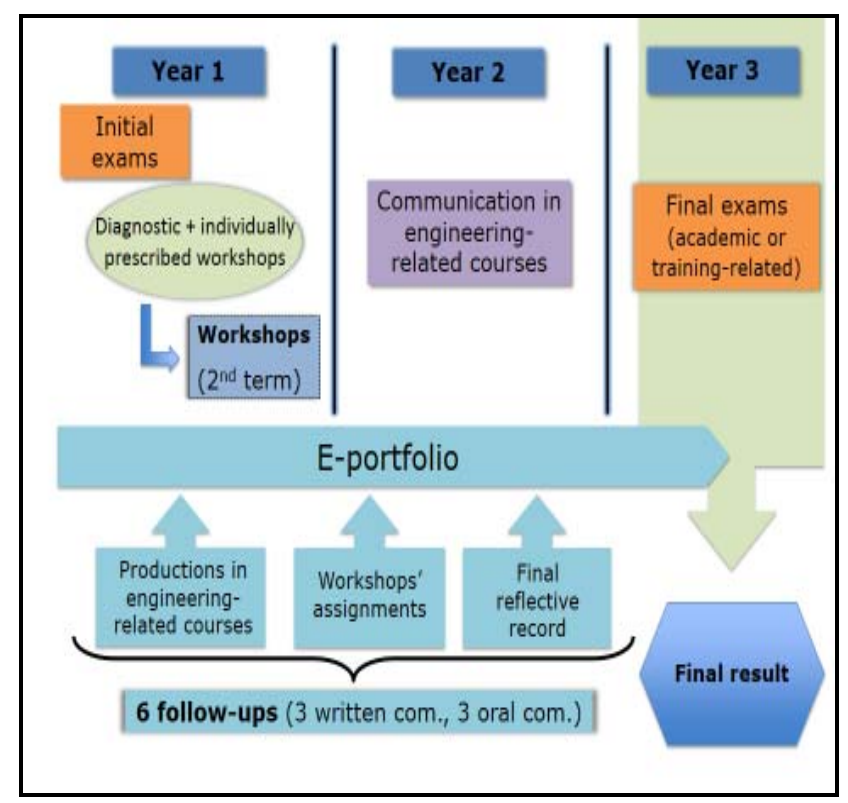

\section{References}

[1] Thomas K. Grose, "Wow the audience", PRISM, vol. 22, no. 4, December 2012. Available from http://www.prismmagazine.org/dec12/tt_01.cfm 